\title{
Diagnosis, Classification and Natural History of Degenerative Dementias
}

\author{
H. Feldman and A. Kertesz
}

\begin{abstract}
The release of the first approved medications for the treatment of Alzheimer's disease in Canada has highlighted the renewed need and importance of diagnostic accuracy and understanding of the spectrum of the dementias. The epidemiological scope of the problem of dementia in Canada including risk factors, caregiving patterns and costs of care have been well-characterized through the Canadian Study of Health and Aging (CSHA 1991-1996) with some of the key findings reviewed here. Beyond Alzheimer's disease the phenotypes and genotypes of the other degenerative dementias have been emerging with proposed operational diagnostic criteria that should facilitate their recognition in clinical practice. This paper reviews the clinical phenotypes of the most common causes of dementia with a proposed classification scheme and with discussion of their relevance from a differential treatment standpoint. This paper served as a background document for the working group of the Consensus Conference on Dementia (C3D) in February 1998 and has been revised subsequently for this publication.
\end{abstract}

RÉSUMÉ: Diagnostic, classification et histoire naturelle des démences dégénératives. L'apparition sur le marché des premiers médicaments approuvés pour le traitement de la maladie d'Alzheimer au Canada a souligné la nécessité et l'importance de l'exactitude du diagnostic et la compréhension du spectre des démences. L'envergure épidémiologique du problème de la démence au Canada incluant les facteurs de risque, les modalités de soins et le coût des soins a été bien caractérisée par l'Étude canadienne sur la santé et le vieillissement (ÉCSV1991-1996) dont nous revoyons ici les observations principales. Au-delà de la maladie d'Alzheimer, les phénotypes et génotypes des autres démences dégénératives sont maintenant mieux définis et des critères diagnostiques opérationnels ont été proposés, ce qui devrait faciliter leur identification en pratique clinique. Cet article a servi de référence pour le groupe de travail de la Conférence de consensus sur la démence (C3D) en février 1998 et a été révisé subséquemment pour la présente publication.

Can. J. Neurol. Sci. 2001; 28: Suppl. 1 - S17-S27

A variety of operationalized diagnostic criteria have been developed for the spectrum of degenerative dementias. These have aimed to allow clinicians more accurate clinical pathological diagnostic accuracy.1,2 For a general dementia diagnosis the criteria most widely used in North America over the past decade have been those of the DSM-IIIR and DSM-IV ${ }^{3,4}$ (Appendix A). Others include the ICD-10 and CAMDEX ${ }^{5-7}$ The general approach of most operationalized diagnostic criteria for an etiologically undifferentiated dementia has been to anchor diagnosis around an impairment of memory and new learning and to couple this with at least one other area of cognitive dysfunction. The involvement of executive function, including initiation, planning, judgement, and decision making has been a recent addition, as it has been noted to be a sensitive domain in dementia. The changes in cognitive function are specified to represent a decline from premorbid levels of competence and are accompanied by declining functional abilities. Behavioral changes are considered to be part of the clinical spectrum but are not specified as being required for a dementia diagnosis. The timeline is not usually specified, however, for a degenerative dementia evolution over a period of six months is usually elicited by the time of diagnosis. Table 1 outlines a current classification of the degenerative dementias.

At the same time that formal operationalized dementia diagnostic criteria have represented a step forward in approach, their use has highlighted their deficiencies. The concordance of diagnostic criteria has been lower than desired. Erkinjuntti et $\mathrm{al}^{8}$ applied eight sets of diagnostic criteria to a group of 1879

From the Division of Neurology, UBC Hospital, Vancouver, BC (HF), and Department of Clinical Neurological Sciences, St. Joseph's Health Centre, London ON (AK) Canada.

Reprint requests to: Howard Feldman, Division of Neurology, UBC Hospital S1922211 Wesbrook Mall, Vancouver, BC Canada V6T2B5 
Table 1: Classification of degenerative dementias

1) Alzheimer's disease (AD)

2) Dementia with Lewy bodies (DLB)

3) Pick Complex or Frontotemporal Degenerations (FTD)

i. Pick's disease

ii. Frontotemporal dementia with motor neuron disease (MND)

iii. Corticobasal degeneration (CBD)

iv. Primary progressive aphasia (PPA)

4) Vascular dementia (VaD)

i. Lacunar Disease

vi. Anoxic Encephelopathy

ii. Multiinfarct type (large vessel) vii. Amyloid Angiopathy

iii. Binswanger's disease viii. Cerebral Angiitis

iv. Watershed Ischemia ix. CADASIL

v. Strategic infarcts $\quad x$. Other

5) Mixed dementia (more than 1 of the above)
i. $\mathrm{AD}$ and $\mathrm{VaD}$
ii. AD and DLB
iii. Other combinations

6) Other degenerative dementias

i. Huntington's disease

ii. Progressive Supranuclear Palsy

iii. Parkinson's disease

iv. Other

Table 2: Frequency of dementia according to defining criteria $(\mathrm{CSHA})^{8}$

\section{Electronic reproduction not granted}

from Erkinjuntti T, Ostbye T, Steenhuis $R$, Hachinski V. The effect of different diagnostic criteria on the prevalence of dementia. $N$ Engl J Med 1997;337:1667-1674. ${ }^{8}$ Reproduced with permission. Copyright (C) 1997 Massachusetts Medical Soceity. All rights reserved

subjects from the Canadian Study of Health and Aging (CSHA) and found a $26 \%$ difference in the frequency of dementia based on the criteria applied as outlined in Table 2.

Similarly for vascular dementia (VaD), Verhey et $\mathrm{al}^{9}$ applied seven sets of criteria for $\mathrm{VaD}$ on a sample of 124 cases, reporting that $36 \%$ had $\mathrm{VaD}$ according to at least one set of criteria but only $7 \%$ according to all criteria. Despite this low concordance of diagnostic criteria the anchoring elements of dementia including progressive cognitive decline and neurobehavioral change should be apparent in each diagnosed case.

\section{Alzheimer's Disease}

The general diagnostic criteria for dementia have been developed around the phenotype of Alzheimer's disease (AD) which is clearly the largest single cause of degenerative dementia. ${ }^{10,11}$ The phenotype of AD centers around an amnesic disorder as the cornerstone of diagnosis which develops with the pathological degeneration of the basal forebrain and its synaptic network to the hippocampus, amygdala, and neocortex. The NINCDS-ADRDA criteria for AD, which have been used since 1984, describe the clinical features that are consistent or inconsistent with the disease ${ }^{12}$ (Appendix B). When applied with the DSM criteria, a clinical pathological accuracy of $80-90 \%$ can be achieved with highly selected cases. ${ }^{1,2}$ However, specificity has been much lower in other less selected series (23-73\%). ${ }^{13-15}$ Blacker et $a{ }^{16}{ }^{16}$ in studying the diagnostic accuracy of the NINCDS-ADRDA criteria, pointed out that errors occur when the history is not fully obtained and when the need for necessary additional history is not pursued. Other errors occur when key clinical features, such as early and prominent behavioral or language changes, are not given appropriate diagnostic weighting, or when co-morbid problems such as stroke or alcoholism are emphasized diagnostically despite the course and phenomenology of the dementia being most typical nonetheless of $\mathrm{AD}$.

\section{OTHER DEGENERATIVE DEMENTIAS}

In contrast to an $\mathrm{AD}$ diagnosis, there are clear deficiencies in applying the DSM or other general dementia criteria to the other degenerative dementias including those outlined earlier in Table 1. In particular, the phenotypes of the frontotemporal dementias (FTD), ${ }^{17,18}$ vascular dementia syndromes, ${ }^{19,20}$ and dementia with Lewy bodies (DLB) ${ }^{21}$ are not easily or well-identified with DSM dementia criteria. ${ }^{22}$ For each of these disorders there have been recently operationalized criteria proposed through consensus meetings with resultant publications that are allowing the phenotypes to be tested. ${ }^{23-27}$ As some of these disorders require primary or secondary treatment interventions and differential pharmacological management, familiarity will be imperative for primary care physicians and specialists who are involved in the care of dementia. The era where such distinctions were only of academic significance is over.

\section{DEMENTIA WITH LEWY BODIES}

Amongst the primary degenerative dementias is DLB, a disorder that has been proposed to have both distinctive phenotypic and neuropathological features. ${ }^{28}$ Nosologically it has been referred to variably as senile dementia of the Lewy body type, dementia associated with cortical Lewy bodies, diffuse Lewy body disease, and the Lewy body variant of AD. ${ }^{21,29-31}$ The Lewy body, a neuronal cytoplasmic inclusion, is the pathological hallmark of the dementia with distribution about the brain stem, cortex, and limbic pathways.

Clinically the phenotype of DLB includes a cognitive disorder that is prominent and progressive. There are fluctuations in the cognitive disorder that can occur over periods of hours, days or weeks. During fluctuations, cognitive function can range from near normal to markedly impaired. However, the decline is 
progressive with time. The patterns of fluctuations can suggest a state of recurrent or chronic delirium, yet workup for toxic/metabolic causes, cerebrovascular events, and intercurrent illness is negative. The cognitive deficits particularly involve attention and executive functions, with a particular prominence of visuospatial impairments. Memory can be relatively preserved early on.

Behaviorally there are usually prominent and persistent visual hallucinations, with recurrent and well-formed features often of people and animals coming into the home. In comparing the visual hallucinations between DLB and AD, it has been reported that in DLB they are more prevalent, more likely to be multiple, to speak, and to be persistent. ${ }^{32}$ Mild Parkinsonism is often identified in DLB and may be the presenting symptom with rigidity and bradykinesia but not commonly resting tremor. DLB can also overlap clinically with classical Parkinson's disease with dementia, as well as with $\mathrm{AD}$ with Parkinsonism.

Neurochemically there is a more significant regional diminution of acetylcholine (Ach) in DLB than in AD. The neuronal losses in the nucleus basalis of Meynert in DLB has been reported to be larger than the corresponding losses in $\mathrm{AD} .^{33}$ The combination of neuronal loss and Lewy body formation in the nucleus basalis of Meynert likely contribute to the reduction in cortical choline acetyltransferase in DLB. ${ }^{33}$ The combination of deep cholinergic deficits in DLB, coupled to Lewy body pathology, support the contention that it is a distinct disorder. ${ }^{34,35}$

There are distinctive pharmacological management considerations for this dementia. Management of behavioral manifestations is challenging, as there is an important neuroleptic hypersensitivity with this disease. The use of traditional neuroleptics has been associated with severe complications, such as neuroleptic malignant syndrome ${ }^{36}$ and shortened survival, and should be avoided. The safety of the newer atypical neuroleptics, such as respiridone, olanzepine and quetiapine, has not been established in DLB and must also be used with great caution until data to the contrary is reported. There are recent data emerging that the symptoms of DLB can be treated effectively with cholinesterase inhibitors. ${ }^{37,38}$ A recently reported randomized double-blind placebo-controlled parallel group study of rivastigmine for the treatment of DLB reported both cognitive and behavioral benefits for rivastigmine during a 12 week trial. ${ }^{38}$ Though there is theoretical concern about AchEIs worsening Parkinsonian signs in DLB, this did not emerge as a problem in this rivastigmine study. ${ }^{38}$

An international consensus paper was published in $1996^{21}$ providing a proposed clinical and neuropathological framework for diagnosis (Appendix C). These proposed diagnostic criteria have since been shown to have very good specificity in the range of $85-90 \%$. However, they have had a much lower sensitivity $(20-40 \%)$ in some reports. ${ }^{27,39}$ The coexistence of mixed pathologies in $1 / 3$ of cases has limited the diagnostic sensitivity of the DLB diagnostic criteria. ${ }^{39,40}$ The pathological diagnostic criteria for DLB emphasize the presence of Lewy Bodies in cortical, limbic, and brain stem structures, frequently but not always associated with senile neuritic plaque scores sufficient to meet CERAD AD diagnostic criteria. ${ }^{41-43}$ There are a minority of reported cases of DLB where senile neuritic plaques are not present and CERAD criteria are not met. ${ }^{30}$

Given that these consensus criteria are relatively recent it has not been possible to assess the prevalence of DLB in population based samples. In a survey of selected Canadian dementia research centers (C5R) there was a reported range of prevalence of $1-10 \%$ of referred subjects with DLB across the eight centers.

\section{Pick Complex OR Frontotemporal degenerations}

In contrast to $\mathrm{AD}$, individuals with dementia resulting from frontotemporal degeneration may have no significant memory impairment initially. Rather they present with behavioral changes or language disorders. Such patients, on the basis of this relative sparing of memory, may not fulfil the general dementia criteria as they are specified in the DSM criteria, yet it is clinically apparent that they have a dementia nonetheless. If, in fact, more comprehensive and increasingly difficult memory tests are given, it is usually possible to show changes even in early cases of FTD in underlying attention or concentration abilities. Frontotemporal dementia is defined by a progressive loss of behavioral control that, as a rule, is frequently accompanied by impaired expressive language commencing in the presenium (under age 65). The presenting features of the FTDs allow some clinical phenotypic fractionation. However, such etiologic subclassification is not always possible. The Lund Manchester working group on FTD has proposed a checklist approach to a rather lengthy list of clinical features. ${ }^{17}$ Over time this checklist seems likely to evolve into a validated set of diagnostic criteria. The core neurobehavioral features of FTD include apathy, loss of personal hygiene, loss of social awareness, disinhibition, mental rigidity, inflexibility, hyperorality, perseverative behavior, utilization behavior, distractibility and loss of insight. The presenting apathy, indifference, remoteness, inertia and aspontaneity are often mistaken for depression. The progressive impairment of expressive language that develops, with reduced speech, eventually mutism, with the concomitant disinhibition, clearly indicates to clinicians that there is more than a depressive episode at hand.

The approaches to the classification of the FTDs have been based either on clinical or pathological features, which has tended to create a nosological dichotomy. Pick originally described the clinical syndrome of FTD and progressive aphasia that came to be known as Pick's disease. However, this disease was subsequently defined by the histopathology of Pick bodies, the round, silver staining inclusions in the dentate gyrus of the hippocampus and the frontotemporal cortex. It was more recently recognized that the majority of clinical Pick's disease do not have actual Pick body pathology thereby creating nosological confusion. ${ }^{44}$ The authors feel that a histologically based definition of Pick's disease cannot provide an acceptable framework for clinicians. It fosters the idea that this disease is rare and it is not diagnosable in vivo, neither of which is correct.

Though there has not yet been consensus on the classification of this spectrum of degenerative dementias that affect frontotemporal regions, a broader based framework called Pick complex is proposed to encompass the clinical syndromes of FTD, including the FTD of motor neuron disease (MND), primary progressive aphasia (PPA), semantic dementia and corticobasal degeneration syndrome (CBDS) $)^{45,46}$ (Table 1).

Primary progressive aphasia was initially identified as a 
unique disorder in 1982 by Mesulam et al ${ }^{47}$ It is characterized by the initial loss of language without dementia. The dementia becomes apparent with longer term follow-up when there are also accompanying behavioral and extrapyramidal components. The aphasia may be nonfluent with stuttering and verbal apraxia but, in most cases, it is a progressive anomia and logopenia. Later all patients with this disorder become less and less fluent with eventual mutism.

In semantic dementia the meaning of concrete nouns and perceived objects initially is lost in a dramatically isolated fashion, with dementia and progressive mutism emerging with time. Behavioral and personality changes are part of this evolving dementia as well.

The CBDS is characterized by an extrapyramidal-apraxic motor disorder that typically includes asymmetrical limb rigidity and akinesia, with dystonia and myoclonus. There is a later gait disorder and disequilibrium. There are often prominent cortical sensory signs, particularly an alien hand disorder with apraxia. Cognitively there is frequently a progressive language impairment with anomic, Broca's, or transcortical motor aphasia in about $50 \%$ of cases. ${ }^{48}$ It has been noted that depression is particularly common in this disorder. ${ }^{49}$

The nosology of 'Pick Complex' is supported by the overlap of clinical and pathological features of these entities as well as by the emerging genetic data on the chromosome 17 linked FTD. ${ }^{46}$ Tau gene mutations on chromosome 17 have been described with many of the clinical syndromes of FTDs. ${ }^{50-53}$ In these autosomal dominant "tauopathies" there are tau positive intraneuronal and glial pathologies. The clinical variants associated with tau mutations include FTD, PPA and CBDS. ${ }^{54}$ Beyond these tauopathies, there is overlap as well in the tau negative pathologies. Tau negative, ubiquitin positive, intracytoplasmic inclusions, that were formerly associated with the MND form of FTD, are now recognized to present with clinical features of either FTD, CBDS or PPA without MND. ${ }^{55}$ It has been reported that the spectrum Pick complex may actually account for 15$25 \%$ of degenerative dementias. ${ }^{56}$ Therefore Pick complex, including both classical Pick's disease and these related disorders, is one of the largest nosological entities after AD to cause dementia, particularly under the age of 65 . This has important implications in future research of the biology and treatment of the dementias.

\section{VASCULAR DEMENTIA}

Vascular dementia remains an elusive entity defying a precise definition. The definitions that emerged during the 1990s were developed specifically for $\mathrm{VaD}$, including the NINDS-AIREN and California Criteria. ${ }^{19,20}$ Some of their core features are in conflict with the DSM-IV definition. ${ }^{4}$ DSM-IV specifies that for $\mathrm{VaD}$, as for $\mathrm{AD}$, there must be memory impairment, as a core feature. The NINDS-AIREN and California criteria by contrast, define the cognitive deficits for diagnosis as involving multiple domains of cognition without a stipulation for memory impairment. ${ }^{4,19,20}$ The DSM-IV allows a diagnosis of VaD to be made on the basis of either clinical signs or neuroimaging, while the NINDS-AIREN "clinically probable" VaD and the California criteria describe a relationship and co-existence between clinical signs, neuroimaging and the diagnosis. ${ }^{19,20}$ This distinction is particularly important with the recognition that it may be either cognitive changes, personality or mood changes that often signal the prelude of a cerebrovascular syndrome. ${ }^{57}$ The debate over definition ranges from the earliest concepts of multiple infarct dementia $^{58}$ to a more recent perspective which urges abandoning the concept of $\mathrm{VaD}$ in favour of a syndrome of "vascular cognitive impairment" (VCI) where the brain injury and syndrome is understood on the basis of the location and extent of cerebrovascular mechanisms. ${ }^{59,60}$ Despite the disagreements over definitions, it is widely appreciated that there is a range of vascular syndromes that can be considered as associated with VCI and dementia as it is variably defined. In addition to multiinfarct dementia (large vessel), lacunar strokes, Binswanger's disease, watershed ischemia, anoxic encephalopathy, amyloid angiopathy, cerebral angiitis and, more recently, described CADASIL(syndrome of autosomal dominant subcortical strokes with leukoariosis and notch three defects in chromosome 19 in some cases), ${ }^{61,62}$ can all cause VCI or dementia as it is variably defined. There is also the important link between vascular lesions and $\mathrm{AD}$, both where lesions of both diseases coexist as well as for their pathogenetic interrelationships. Snowdon et $\mathrm{al}^{63}$ have reported that small, and apparently clinically silent, lacunes and periventricular white matter lesions have a significant role in unmasking AD.

One of the cerebrovascular syndromes, that of subcortical $\mathrm{VaD}$, is gaining particular importance as a proposed phenotype that might serve to test emerging vascular therapies. ${ }^{64,65}$ Clinically, in subcortical $\mathrm{VaD}$ there is often a history of small strokes or of multiple transient ischemic attacks without residual symptoms. On the elemental neurological exam, abnormal findings may be limited to minor focal features such as reflex asymmetries, or drift. There may be a disorder of gait, with shuffling and apraxic features. Cognitively, there is often a dysexecutive syndrome that includes an impairment in frontal lobe cognitive functioning [e.g. initiation, planning, organizing, set shifting, abstraction, impairments]. The memory deficits can be mild, with impaired free recall and with benefits from cued recall. Recognition memory often remains relatively intact and there is less severe forgetting, a pattern that would be atypical for AD. Behavioral and psychological symptoms often include depression, personality change, emotional incontinence and psychomotor retardation. ${ }^{64,65}$ Other behavioral manifestations may include inattention, abulia and disinhibition. This clinical entity of subcortical $\mathrm{VaD}$ incorporates small vessel diseases such as Binswanger's disease and lacunar disease, with the primary brain lesions being either lacunar infarctions or ischemic white matter lesions subcortically. Neuroimaging is evidently required to support the clinical diagnosis of subcortical $\mathrm{VaD}$. It has been proposed that subcortical $\mathrm{VaD}$ will show a predictable clinical picture, natural history, outcome and treatment responses and that it will be suitable for clinical trials research. Further empirical data will be required to validate this approach.

Out of the debates over VaD some additional concepts have become widely accepted. Whereas in the original descriptions of Tomlinson et $\mathrm{al}^{66}$ infarct volumes of 50-100 cc were considered the minimum to produce $\mathrm{VaD}$, it is now recognised that "strategic infarctions" as small as $10 \mathrm{cc}$ can cause a dementia syndrome with significant memory loss and confusion with, or without, an evident focal neurological deficit. Such strategic 
lesions may occur in the thalamus, left posterior parietal lobe, basal forebrain in the territory of the anterior communicating artery, or angular gyrus.

\section{EPIDEMIOLOGYAND RISK FACTORS FOR DEMENTIA}

The current rapid and projected growth of the population above age 65 in Canada has been emphasized in demographic studies. The segment of the population over the age of 85 is the most rapidly growing one within Canadian society. ${ }^{67}$ In the face of these changing demographics, the population based CSHAset out in 1990-91 to estimate the prevalence of dementia over age $65,{ }^{10}$ the risk factors for dementia ${ }^{68}$ and the estimated costs of dementia. ${ }^{69}$ This study, (CSHA I) laid the groundwork for an incidence study, CSHA II, that was performed in 1996. CSHAII additionally included an investigation of the clinical progression of dementia, a prospective study of risk factors, and a study of the outcomes of mild cognitive impairment nosologically referred to as "Cognitively Impaired Not Demented" in CSHA. ${ }^{70}$

In CSHA-I there were 9008 community and 1255 institutionalized subjects sampled in the prevalence study. ${ }^{10}$ Between ages 65-74 there was an estimated 2\% prevalence of dementia that increased to $12 \%$ between ages 75-84 and further increased to $35 \%$ over age 85 . The incidence rates from CSHAII demonstrated roughly a doubling of incident rates each five years after age 65 in both males and females. ${ }^{70}$

Risk factor data were collated for $\mathrm{AD}^{68}$ and $\mathrm{VaD}^{71}$ from a case control study from CSHA-I. These risk factors are outlined in Tables 3 and 4 respectively.

\section{AlZHeIMER's DiSEASE RISK FACTORS}

For AD the most significant risk factors include age, then a positive family history of first degree relatives with either AD or other dementia, a formal education of 6 years or less, and a prior history of head injury (Table 3 ). These risk factors have been consistently identified, not only from the case control study of CSHA, but also from other major epidemiological studies such as the European based EURODEM. ${ }^{72-80}$ There was no confirmation from CSHA of the EURODEM finding that smoking and thyroid disease were inversely related to the risk of $\mathrm{AD}^{76,78}$ or that wine drinking was protective. ${ }^{81}$ In both epidemiological studies there was a noted decreased risk of $\mathrm{AD}$ associated with the presence of arthritis and with the use of nonsteroidal anti-inflammatory drugs (NSAIDs) with potential implications for dementia prevention. There was a suggestion that there were associations between occupational exposure to glues, pesticides and fertilizers in CSHA but they were noted to require more detailed prospective study. ${ }^{68}$

In addition to the risk factors elicited in CSHAthere has been an emerging awareness of the potential role of estrogens in reducing the risk of acquiring AD. Estrogens are neurobiologically active, crossing the blood brain barrier and interacting with estrogen receptors on neurons including those at the basal forebrain. ${ }^{82}$ Estrogens have a putative role on neuronal plasticity, synaptogenesis and repair while physiologically they enhance long-term potentiation. ${ }^{83,84}$ In epidemiological studies there have been several case control studies which have reported a lowered use of postmenopausal estrogens in AD than control subjects. ${ }^{85,86}$ Paganini-Hill et al ${ }^{87}$ reported an odds ratio of 0.69
Table 3: Risk Factors for AD (CSHAI $)^{68}$

\section{Electronic reproduction not granted}

The Canadian Study of Health and Aging. The Canadian Study of Health and Aging: risk factors for Alzheimer's disease in Canada. Neurology 1994;44:2073-2080. Reproduced with permission of Lippincott, Williams and Wilkins

of developing $\mathrm{AD}$ in women using estrogens in a prospective longitudinal cohort study. The risk reduction was associated with both increased dose and duration of estrogen use. Similar findings of relative risk reduction, associated with the use of estrogens, have been noted in the prospective studies of the Baltimore Longitudinal Study of Aging ${ }^{88}$ and the northern Manhattan study, ${ }^{89}$ though a prospective study by an HMO in Puget Sound did not find this same association.

This research on risk factors for $\mathrm{AD}$ has kindled interest in preventive trials of both postmenopausal estrogen replacement therapy for women and NSAIDs. Thal ${ }^{90}$ has hypothesized that "Given that the prevalence doubles every five years, delaying the onset of appearance of disease by five years would result in a $50 \%$ reduction in prevalence in one generation. Delaying onset by ten years would halve the prevalence again, reducing it by $75 \%$ in a generation. Thus, primary prevention would have maximal cost benefit." It is anticipated that, over the next five to ten years, the long-term prospective cohort studies, that will be required to allow clinicians the evidence about long-term preventive therapies, will be obtained.

Amongst the biological genetic markers for AD, it has been the apolipoprotein E (ApoE) that to date has been associated with the most identifiable risk of acquiring either sporadic or familial late onset $\mathrm{AD} .{ }^{91}$ ApoE is a plasma lipoprotein which is involved in cholesterol transport and regulation. In brain, it is produced by astrocytes and, amongst its functions, it appears to be involved in synaptogenesis and neuronal repair. Its gene is found on the long arm of chromosome 19, where it exists in 3 alleles (ApoE2, ApoE3 or ApoE4). The alleles encode different forms of the apolipoprotein, which have different amino acids at one or both of two sites resulting in different physical and biochemical properties of each lipoprotein..$^{92}$ One such allele is inherited from each parent with six possible genotypes resulting. The presence of the $\mathrm{E} 4$ allele is associated with an increased risk of $\mathrm{AD}$ and a decreased age of disease onset. ${ }^{91}$ One E4 allele is associated with an increased risk of 2.2-4.4 while the E4/E4 genotype increases the risk to 5.1-17.9. ${ }^{93-95}$ Persons with the E4 genotype carry a 
higher risk as well, if there are relatives who have been diagnosed with AD. However, this is only a risk marker, as some ApoE4 carriers survive to old age and can remain cognitively normal. From population studies it is clear that there are E4 individuals who remain cognitively normal. ${ }^{96}$ Hence having the E4 genotype attributes a risk relationship only. There has been some suggestion that the E4 genotype is associated with a lack of response to cholinesterase inhibitors, though these preliminary observations require more detailed study. On the basis of currently available information, the Lancet consensus conference $^{92}$ concluded that use of Apo E genotyping was not recommended for asymptomatic individuals and should not be used as the sole diagnostic test in symptomatic patients. Additionally, genotype disclosure can have adverse effects on insurability, employability and psychosocial status. The Lancet consensus group also made the recommendation that genotyping was not appropriate to be used in routine clinical practice. ${ }^{92}$

\section{VASCULAR DEMENTIA RISK FACTORS}

For $\mathrm{VaD}, \mathrm{CSHA}^{71}$ risk factors included a history of arterial hypertension, history of alcohol abuse, history of heart disease, use of ASA, education less than six years and occupational exposures including pesticides and herbicides, liquid plastic and rubber. Table 4 outlines these risk factors.

Other epidemiological studies have shown that hypertension is a risk factor for late life cognitive impairment as well as AD. ${ }^{97,98}$ In CSHA, a history of diabetes mellitus and smoking were not associated with an increased $\mathrm{VaD}$ risk as reported by other groups. ${ }^{99}$ A basal metabolic index (wt in kgs/height in $\mathrm{m}^{2}$ ) of $<20$ was associated with a near significant increased risk to $\mathrm{VaD}$, extending an observation from other studies. ${ }^{100}$

The potential for treatment of hypertension to reduce the incidence of dementia has been suggested by the promising results of the SYST-EUR trial ${ }^{101}$ where the incidence of dementia was halved treating with nitredine, a calcium channel blocker, supplemented with enalapril and a thiazide as required

Table 4: Risk Factors for $\mathrm{VaD}(\mathrm{CSHA})^{71}$

\section{Electronic reproduction not granted}

Adapted from Lindsay J, Hebert R, Rockwood K. The Canadian Study of Health and Aging: risk factors for vascular dementia. Stroke 1997;28:526-

530. Reproduced with permission. () 1997 American Heart Association

\section{Electronic reproduction not granted}

Figure: Typical course of Alzheimer's disease over time. ${ }^{114}$

CDR, Clinical Dementia Rating; GDS, Global Deterioration Scale; FAST, Functional Assessment Staging Measure; MMSE, Mini-Mental Status Exam; Blessed IMC, Information, Memory and Concentration Test.

Modified from Reisberg B, Sclan SG, Franssen E, Kluger A, Ferris SH. Dementia staging in chronic care populations. [Review]. Alzheimer Dis Assoc Disord 1994;8 (Suppl 1):S188-S205. ${ }^{114}$ Reproduced with permission.

for BP control. Other studies have made contradictory findings. ${ }^{102}$ Further replication of these beneficial results of SYST-EUR will be required.

\section{NATURAL HISTORY OF THE DEMENTIAS}

Alzheimer's disease, being the most frequent dementia, has also been the best characterized in naturalistic studies. ${ }^{103-105}$ Unfortunately at present, despite the claims, there is no biological marker, neuroimaging study, or blood test that can reliably determine rates of decline in an individual patient. ${ }^{106-111}$ Without such a biological marker, the course of the disease must be assessed through clinical evaluation. There have been a variety of disease staging instruments that have been developed to assist such longitudinal evaluation. Some, such as the Global Deterioration Scale (GDS) ${ }^{104}$ and Functional Assessment Scale (FAST), ${ }^{112}$ can be easily done in an office setting. They cover key elements of $\mathrm{AD}$ and other dementias by tapping into cognitive, behavioral and functional domains affected in the disease. Using these staging scales Reisberg et al $^{113}$ have plotted the course of $\mathrm{AD}$ onto a natural history grid which can be used for reference in the follow-up assessments of patients. The Figure, adapted from Reisberg, ${ }^{114}$ shows the typical course of AD over time according to some of the common staging instruments. Such a grid can be effective in setting expectations of patients, caregivers and families for the road that is ahead at the time of diagnosis and in follow-up assessments.

In framing expectations for the survival of $\mathrm{AD}$ patients from the time of diagnosable $\mathrm{AD}$, in general terms the estimated survival will be an average of 8-12 years. It must be emphasized, however, that such rates of decline are quite heterogeneous with both rapid and slow decliners, outside of the predicted rates. ${ }^{28,115}$ Amongst the rapid decliners have been those individuals with early and prominent aphasia, ${ }^{116,117}$ extrapyramidal signs, ${ }^{118,119}$ and early age of onset. ${ }^{120}$

One of the current challenges, with the advent of therapy for $\mathrm{AD}$, is to gauge treatment response against a background of the natural history of the disease. The current approved medications for $\mathrm{AD}$, the cholinesterase inhibitors, have targeted symptomatic benefits as their indication for use, while longer-term effects on 
disease progression have not actually been determined. This deficiency will leave uncertainty for clinicians about the duration of therapy once initiated, as well as the longer-term effects on disease progression. Post regulatory approval, such information will likely be quite difficult to acquire, particularly as the opportunity for placebo controlled settings diminishes.

In the absence of well-validated and agreed upon diagnostic criteria it has been difficult to study naturalistic data for the nonAlzheimer dementias. With the advent of the newly proposed criteria, it may become possible to have better epidemiological and naturalistic data.

\section{Conclusions}

The phenotypes of both AD and other degenerative dementias are becoming better understood, with operational diagnostic criteria for a wider spectrum of the dementias now available. The advances in molecular genetics may hold the key to clarifying some of the difficult interrelationships between these neurodegenerative dementias.

The understanding of the epidemiology of dementia in Canada has been greatly enhanced by the CSHA. Risk factor modification may allow an impact on the incidence of the dementias, a particularly important consideration with the demographic shifts in Canada towards a more elderly population.

The challenges of diagnosis and the emergence of approved treatments for some of the degenerative dementias open a new era where nihilism will have to be challenged and where differential treatment approaches are required. Both primary care physicians and specialists involved in the care of dementia in Canada will have to familiarize themselves with the emerging dementia phenotypes and their treatment. Understanding both dementia risk factors and their modification, as well as the natural history of the dementias will allow confidence in managing dementing illnesses.

\section{ACKNOWLEDGEMENTS}

We thank Agnes Sauter, Sandra Tam and Carmel King for their assistance in the preparation of this work.

\section{REFERENCES}

1. Morris JC, McKeel DW, Fulling K, Torack RM, Berg L. Validation of clinical diagnostic criteria for Alzheimer's disease. Ann Neurol $1988 ; 24: 17-22$.

2. Tierney MC, Fisher RH, Lewis AJ, et al. The NINCDS-ADRDA Work Group criteria for the clinical diagnosis of probable Alzheimer's disease: a clinicopathologic study of 57 cases. Neurology 1988;38:359-364.

3. APA (American Psychiatric Association). Diagnostic and Statistical Manual of Mental Disorders. Third, revised Ed. Washington, DC: American Psychiatric Association, 1987

4. APA (American Psychiatric Association). Diagnostic and Statistical Manual of Mental Disorders. Fourth Ed. Washington, DC: American Psychiatric Association, 1994

5. World Health Organization. ICD-10: International statistical classification of diseases and related health problems: Based on recommendations of the Tenth Revision Conference, 1989 and adopted by the Forty-third World Health Assembly. 1992;10th revision edition:(Abstract).

6. Roth M, Tym E, Mountjoy CQ, et al. CAMDEX - A standardized instrument for the diagnosis of mental disorder in the elderly with special reference to the early detection of dementia. $\mathrm{Br} \mathrm{J}$
Psychiatry 1986;149:698-709.

7. Cummings JL, Benson DF. Dementia: definition, prevalence, classification, and approach to diagnosis. In: Anonymous Dementia: A Clinical Approach. 2nd Ed. Stoneham, MA: Butterworth-Heinemann, 1992:1-17.

8. Erkinjuntti T, Ostbye T, Steenhuis R, Hachinski V. The effect of different diagnostic criteria on the prevalence of dementia. $\mathrm{N}$ Engl J Med 1997;337:1667-1674.

9. Verhey FRJ, Lodder J, Rozendaal N, Jolles J. Comparison of seven sets of criteria used for the diagnosis of vascular dementia. Neuroepidemiology 1996;15:166-172.

10. Canadian Study of Health and Aging Working Group. Canadian Study of Health and Aging: study methods and prevalence of dementia. Can Med Assoc J 1994;150:899-913.

11. Launer LJ, Hofman A. Studies on the incidence of dementia: the European perspective [review]. Neuroepidemiology 1992;11: 127-134.

12. McKhann G, Drachman DA, Folstein M, et al. Clinical diagnosis of Alzheimer's disease - report of the NINCDS-ADRDA Work Group under the auspices of Department of Health and Human Services Task Force on Alzheimer's disease. Neurology 1984;34:939-944.

13. Boller F, Lopez OL, Moossy J. Diagnosis of dementia: clinicopathologic correlations. Neurology 1989;39:76-79.

14. Mayeux R, Saunders AM, Shea S, et al. Utility of the apolipoprotein $\mathrm{E}$ genotype in the diagnosis of Alzheimer's disease. N Engl J Med 1998;338:506-511.

15. Buschke H. Cued recall in amnesia. J Clin Neuropsych 1984;6:433440.

16. Blacker D, Albert MS, Bassett SS, et al. Reliability and validity of NINCDS-ADRDAcriteria for Alzheimer's disease. Arch Neurol 1994;51:1198-1204.

17. Lund and Manchester Groups. Clinical and neuropathological criteria for frontotemporal dementia [review]. J Neurol Neurosurg Psychiatry 1994;57(4):416-418.

18. Kertesz A, Davidson W, Fox H. Frontal behavioral inventory: diagnostic criteria for frontal lobe dementia. Can J Neurol Sci 1997;24:29-36.

19. Roman GC, Tatemichi TK, Erkinjuntti T, et al. Vascular dementia: diagnostic criteria for research studies. Report of the NINDSAIREN International Workshop. Neurology 1993;43:250-260.

20. Chui HC, Victoroff JI, Margolin D, et al. Criteria for the diagnosis of ischemic vascular dementia proposed by the State of California Alzheimer's Disease Diagnostic and Treatment Centers. Neurology 1992;42:473-480.

21. McKeith IG, Galasko D, Kosaka K, et al. Consensus guidelines for the clinical and pathological diagnosis of dementia with Lewy bodies (DLB): report of the consortium on DLB international workshop. Neurology 1996;47:1113-1124.

22. Litvan I, Agid Y, Goetz C, et al. Accuracy of the clinical diagnosis of corticobasal degeneration: a clinicopathologic study. Neurology 1997;48:119-125.

23. Miller BL, Ikonte $\mathrm{C}$, Ponton $\mathrm{M}$, et al. A study of the LundManchester research criteria for frontotemporal dementia: clinical and single-photon emission CT correlations. Neurology 1997;48:937-942.

24. Amar K, Wilcock GK, Scott M. The diagnosis of vascular dementia in the light of the new criteria. Age Ageing 1996;25:51-55.

25. Gold G, Giannakopoulos P, Montes-Paixao Jr C, et al. Sensitivity and specificity of newly proposed clinical criteria for possible vascular dementia. Neurology 1997;49:690-694.

26. Mega MS, Masterman DL, Benson DF, et al. Dementia with Lewy bodies: reliability and validity of clinical and pathologic criteria. Neurology 1996;47:1403-1409.

27. McKeith IG, Perry EK, Perry RH. Report of the second dementia with Lewy body international workshop. Neurology 1999;53:902-905.

28. McKeith IG, Ayre GA. Consensus criteria for the clinical diagnosis of dementia with Lewy bodies. In: Iqbal K, Winblad B, Nishimura T, Takeda M, Wisniewski HM, eds. Alzheimer's Disease: Biology, Diagnosis and Therapeutics. Chichester: John Wiley \& Sons Ltd, 1997:167-177. 
29. McKeith IG, Perry RH, Fairburn AF, Jabeen S, Perry EK. Operational criteria for senile dementia of Lewy body type. Psychol Med 1992;22:911-922.

30. Hansen L, Salmon D, Galasko D, et al. The Lewy body variant of Alzheimer's disease: a clinical and pathologic entity. Neurology 1990;40:1-8.

31. Byrne EJ, Lennox G, Lowe J, Godwin-Austen RB. Diffuse Lewy body disease: clinical features in 15 cases. J Neurol Neurosurg Psychiatry 1989;52:709-717.

32. Ballard C, McKeith I, Harrison R, et al. A detailed phenomenological comparison of complex visual hallucinations in dementia with Lewy bodies and Alzheimer's disease. Int Psychogeriatr 1997;9:381-388.

33. Lippa CF, Smith TW, Perry E. Dementia with Lewy bodies: choline acetyltransferase parallels nucleus basalis pathology. J Neural Transm 1999; 106:525-535.

34. Perry EK, Haroutunian V, Davis KL, et al. Neocortical cholinergic activities differentiate Lewy body dementia from classical Alzheimer's disease. Neuroreport 1994;5:747-749.

35. Dickson DW, Davies P, Mayeux R, et al. Diffuse Lewy body disease. Neuropathological and biochemical studies of six patients. Acta Neuropathol (Berl.) 1987;75:8-15.

36. McKeith IG, Fairbairn A, Perry RH, Thompson P, Perry E. Neuroleptic sensitivity in patients with senile dementia of Lewy body type. BMJ 1992;305:673-678.

37. Shea C, MacKnight C, Rockwood K. Donepezil for treatment of dementia with Lewy bodies: a case series of nine patients. Int Psychogeriatr 1998;10:229-238.

38. McKeith I, Del-Ser T, Anand R, et al. Rivastigmine provides symptomatic benefit in dementia with Lewy bodies: Findings from a placebo-controlled international multicenter study. Neurology 2000;54:A450(Abstract)

39. Holmes C, Cairns N, Lantos P, Mann A. Validity of current clinical criteria for Alzheimer's disease, vascular dementia and dementia with Lewy bodies. Br J Psychiatry 1999;174:45-50.

40. Barber R, Scheltens P, Gholkar A, et al. White matter lesions on magnetic resonance imaging in dementia with Lewy bodies, Alzheimer's disease, vascular dementia, and normal aging. J Neurol Neurosurg Psychiatry 1999;67:66-72.

41. Mirra SS, Gearing M, Heyman A. CERAD guide to the neuropathological assessment of Alzheimer's disease and other dementias. For information contact: Albert Heyman MD, Box 3203 Duke University Medical Center, Durham NC 27710 USA. 1994.

42. Hansen LA, Samuel W. Criteria for Alzheimer's disease and the nosology of dementia with Lewy bodies. Neurology 1997;48: 126-132.

43. Mirra SS, Gearing M, Nash F. Neuropathological assessment of Alzheimer's disease. Neurology 1997;49(suppl 3):S14-S16

44. Knopman DS, Mastri AR, Frey WH, Sung JH, Rustan T. Dementia lacking distinctive histologic features: a common non-Alzheimer degenerative dementia. Neurology 1990;40:251-256.

45. Kertesz A, Hudson L, Mackenzie IRA, Munoz DG. The pathology and nosology of primary progressive aphasia. Neurology 1994;44:2065-2072.

46. Kertesz A, Munoz DG. Pick's Disease and Pick Complex. New York:Wilem-Liss, 1998.

47. Mesulam MM. Slowly progressive aphasia without generalized dementia. Ann Neurol 1982;11:592-598.

48. Frattali CM, Grafman J, Patronas N, Makhlouf F, Litvan I. Language disturbances in corticobasal degeneration. Neurology 2000;54:990-992.

49. Cummings JL, Litvan I. Neuropsychiatric aspects of corticobasal degeneration. Adv Neurol 2000; 82:147-152.

50. Foster NL, Wilhelmsen K, Sima AA, et al. Frontotemporal dementia and parkinsonism linked to chromosome 17: a consensus conference. Conference Participants. [Review]. Ann Neurol 1997;41:706-715.

51. Spillantini MG, Goedert M, Crowther RA, et al. Familial multiple system tauopathy with presenile dementia: a disease with abundant neuronal and glial tau filaments. Proc Natl Acad Sci USA1997;94(8):4113-4118.
52. Cooper PN, Jackson M, Lennox G, Lowe J, Mann DM. Tau, ubiquitin, and alpha B-crystallin immunohistochemistry define the principal causes of degenerative frontotemporal dementia. Arch Neurol 1995;52:1011-1015.

53. Froelich S, Basun H, Forsell C, et al. Mapping of a disease locus for familial rapidly progressive frontotemporal dementia to chromosome 17q12-21. Am J Med Gen 1997;74:380-385.

54. Bird TD, Nochlin D, Poorkaj P, et al. A clinical pathological comparison of three families with frontotemporal dementia and identical mutations in the tau gene (P301L) [published erratum appears in Brain 1999 Jul;122(Pt 7):1398]. Brain 1999;122:741756.

55. Kertesz A, Orange JB. Primary progressive aphasia - the future of neurolinguistic and biologic characterization. Brain Lang 2000; 71:116-119.

56. Gustafson L. Clinical picture of frontal lobe degeneration of nonAlzheimer type. Dementia 1993;4:143-148.

57. Erkinjuntti T, Hachinski VC. Rethinking Vascular Dementia. Cerebrovasc Dis 1993;3:3-23.

58. Hachinski VC, Lassen NA, Marshal J. Multi-infarct dementia: a cause of mental deterioration in the elderly. Lancet 1974;2:207210.

59. Rockwood K, Ebly EM, Hachinski VC, Hogan D. Presence and treatment of vascular risk factors in patients with vascular cognitive impairment. Arch Neurol 1997;54:33-39.

60. Rockwood K, Black S, Gauthier S, Feldman H, Wentzel C. Clinical and neuroimaging findings in mixed dementia. Research and Practice in Alzheimer's Disease 2000, 3rd Ed

61. Joutel A, Corpechot C, Ducros A, et al. Notch3 mutations in cerebral autosomal dominant arteriopathy with subcortical infarcts and leukoencephalopathy (CADASIL), a mendelian condition causing stroke and vascular dementia. Ann NY Acad Sci 1997; 826:213-217.

62. Joutel A, Vahedi K, Corpechot $\mathrm{C}$, et al. Strong clustering and stereotyped nature of Notch3 mutations in CADASIL patients. Lancet 1997;350:1511-1515.

63. Snowdon DA, Greiner LH, Mortimer JA, et al. Brain infarction and the clinical expression of Alzheimer's disease: The nun study. JAMA1997;277:813-817.

64. Erkinjuntti T, Inzitari D, Pantoni L, et al. Limitations of clinical criteria for the diagnosis of vascular dementia in clinical trials. Is a focus on subcortical vascular dementia a solution? Ann NY Acad Sci 2000;903:262-272.

65. Erkinjuntti T, Inzitari D, Pantoni L, et al. Research criteria for subcortical vascular dementia in clinical trials. J Neural Transm 2000;59(Suppl):23-30.

66. Tomlinson BE, Blessed G, Roth M. Observations on the brains of demented old people. J Neurol Sci 1970;11:205-242.

67. Statistics Canada. A portrait of seniors in Canada (89-519-XPE). 1996

68. The Canadian Study of Health and Aging. The Canadian Study of Health and Aging: risk factors for Alzheimer's disease in Canada. Neurology 1994;44:2073-2080.

69. Ostbye T, Crosse E. Net economic costs of dementia in Canada. Can Med Assoc J 1994;151:1457-1464.

70. McDowell I. The incidence of dementia in Canada: The Canadian Study of Health and Aging Working Group. Neurology 2000.

71. Lindsay J, Hebert R, Rockwood K. The Canadian Study of Health and Aging: risk factors for vascular dementia. Stroke 1997;28:526-530.

72. van Duijn CM, Stijnen T, Hofman A. Risk factors for Alzheimer's disease: overview of the EURODEM collaborative re-analysis of case-control studies. EURODEM Risk Factors Research Group. Int J Epidemiol 1991;20 (Suppl 2):S4-S12.

73. van Duijn CM, Clayton D, Chandra V, et al. Familial aggregation of Alzheimer's disease and related disorders: a collaborative reanalysis of case-control studies. EURODEM Risk Factors Research Group. Int J Epidemiol 1991;20 (Suppl 2):S13-S20.

74. Rocca WA, van Duijn CM, Clayton D, et al. Maternal age and Alzheimer's disease: a collaborative re- analysis of case-control studies. EURODEM Risk Factors Research Group. Int J Epidemiol 1991;20 (Suppl 2):S21-S27. 
75. Mortimer JA, van Duijn CM, Chandra V, et al. Head trauma as a risk factor for Alzheimer's disease: a collaborative re-analysis of case-control studies. EURODEM Risk Factors Research Group. Int J Epidemiol 1991;20 (Suppl 2):S28-S35.

76. Breteler MMB, van Duijn CM, Chandra V, et al. Medical history and the risk of Alzheimer's disease: a collaborative re-analysis of case-control studies. EURODEM Risk Factors Research Group. Int J Epidemiol 1991;20 (Suppl 2):S36-S42.

77. Jorm AF, van Duijn CM, Chandra V, et al. Psychiatric history and related exposures as risk factors for Alzheimer's disease: a collaborative re-analysis of case-control studies. EURODEM Risk Factors Research Group. Int J Epidemiol 1991;20 Suppl 2:S43-S47.

78. Graves AB, van Duijn CM, Chandra V, et al. Alcohol and tobacco consumption as risk factors for Alzheimer's disease: a collaborative re-analysis of case-control studies. EURODEM Risk Factors Research Group. Int J Epidemiol 1991;20 (Suppl 2):S48-S57.

79. Graves $\mathrm{AB}$, van Duijn $\mathrm{CM}$, Chandra V, et al. Occupational exposures to solvents and lead as risk factors for Alzheimer's disease: a collaborative re-analysis of case-control studies. EURODEM Risk Factors Research Group. Int J Epidemiol 1991;20 Suppl 2:S58-S61.

80. van Duijn CM, Hofman A. Risk factors for Alzheimer's disease: the EURODEM collaborative re-analysis of case-control studies. Neuroepidemiology 1992;11 (Suppl 1):106-113.

81. Orgogozo JM, Dartigues JF, Lafont S, et al. Wine consumption and dementia in the elderly: a prospective community study in the Bordeaux area. Rev Neurol 1997;153(3):185-192.

82. McEwen BS, Alves SE, Bulloch K, Weiland NG. Ovarian steroids and the brain: implications for cognition and aging. Neurology 1997;48(Suppl 7):S8-S15.

83. Ferreira A, Caceres A. Estrogen-enhanced neurite growth: evidence for a selective induction of Tau and stable microtubules. J Neurosci 1991;11(2):392-400.

84. Warren SG, Humphreys AG, Juraska JM, Greenough WT. LTP varies across the estrous cycle: enhanced synaptic plasticity in proestrus rats. Brain Res 1995;703(1-2):26-30.

85. Birge SJ. The role of estrogen deficiency in the aging central nervous system. In: Lobo RA, Ed. Treatment of the postmenopausal woman: basic and clinical aspects. New York: Raven Press, 1994:153-157.

86. Henderson VW, Paganini-Hill A, Emanuel CK, Dunn ME, Buckwalter JG. Estrogen replacement therapy in older women. Arch Neurol 1994;51:896-900.

87. Paganini-Hill A, Henderson VW. Estrogen deficiency and risk of Alzheimer's disease in women. Am J Epidemiol 1994;140:256-261.

88. Kawas C, Resnick S, Morrison A, et al. A prospective study of estrogen replacement therapy and the risk of developing Alzheimer's disease: the Baltimore Longitudinal Study of Aging. Neurology 1997;48:1517-1521.

89. Tang MX, Jacobs D, Stern Y, et al. Effect of oestrogen during menopause on risk and age at onset of Alzheimer's disease. Lancet 1996;348:429-432.

90. Thal LJ, Carta A, Doody R, et al. Prevention protocols for Alzheimer's disease. Alzheimer Dis Assoc Disord 1997;11 (Supp 3):46-49.

91. Corder EH, Saunders AM, Strittmatter WJ, et al. Gene dose of apoliprotein E type 4 allele and the risk of Alzheimer's disease in late onset families. Science 1993;261:921-923.

92. National Institute on Aging, Alzheimer's Association Working Group. Apolipoprotein E genotyping in Alzheimer's disease. Lancet 1996;347:1091-1095.

93. Mayeux R, Stern Y, Ottman R, et al. The apolipoprotein epsilon 4 allele in patients with Alzheimer's disease. Ann Neurol 1993;34:752-754.

94. Lucotte G, David F, Visvikis S, et al. Apolipoprotein E-epsilon 4 allele and Alzheimer's disease. Lancet 1993;342:1309.

95. Nalbantoglu J, Gilfix BM, Bertrand P, et al. Predictive value of apolipoprotein E genotyping in Alzheimer's disease: results of an autopsy series and an analysis of several combined studies. Ann Neurol 1994;36:889-895.
96. Myers RH, Schaefer EJ, Wilson PWF, et al. Apolipoprotien E e4 association with dementia in a population-based study: The Framingham Study. Neurology 1996;46:673-677.

97. Rockwood K. Lessons from mixed dementia [editorial]. Int Psychogeriatr 1997;9:245-249.

98. Skoog I. The relationship between blood pressure and dementia: a review. Biomed Pharmacother 1997;51:367-375.

99. Meyer JS, McClintic KL, Rogers RL, Sims P, Mortel KF. Aetiological considerations and risk factors for multi-infarct dementia. J Neurol Neurosurg Psychiatry 1988;51:1489-1497.

100. Berlinger WG, Potter JF. Low Body Mass Index in demented outpatients. J Am Geriatr Soc 1991;39:973-978.

101. Staessen JA, Fagard R, Thijs L, et al. Randomised double-blind comparison of placebo and active treatment for older patients with isolated systolic hypertension. The Systolic Hypertension in Europe (Syst-Eur) Trial Investigators. Lancet 1997;350:757-764.

102. Maxwell CJ, Hogan DB, Ebly EM. Calcium-channel blockers and cognitive function in elderly people: results from the Canadian Study of Health and Aging. 1999;161 (5):501-506.

103. Galasko D, Edland SD, Morris JC, et al. The Consortium to Establish a Registry for Alzheimer's Disease (CERAD). Part XI. Clinical milestones in patients with Alzheimer's disease followed over 3 years. Neurology 1995;45: 1451-1455.

104. Reisberg B, Ferris SH, de Leon MJ, Crook T. The Global Deterioration Scale (GDS). Psychopharmacol Bull 1988;24(4): 661-663.

105. Feldman H, Schulzer M, Wang S, Tuokko H, Beattie BL. The Functional Rating Scale in Alzheimer's disease assessment: a longitudinal study. Research Advances in Alzheimer's Disease and Related Disorders 1995;235-241.

106. Scheltens P, Leys D, Barkhof F, et al. Atrophy of medial temporal lobes on MRI in "probable" Alzheimer's disease and normal ageing: diagnostic value and neuropsychological correlates. J Neurol Neurosurg Psychiatry 1992;55:967-972.

107. Kennard ML, Feldman H, Yamada T, Jefferies WA. Serum levels of the iron binding protein, $\mathrm{p} 97$ are elevated in Alzheimer's disease. Nat Med 1996;2(11):1230-1235.

108. Licastro F, Davis LJ, Polazzi E, Rossi S, Cucinotta D. Serological alpha 1-antichymotrypsin in patients with probable senile dementia of Alzheimer type: a short-term longitudinal study. Alzheimer Dis Assoc Disord 1996;10:192-196.

109. Laakso MP, Partanen K, Riekkinen P, et al. Hippocampal volumes in Alzheimer's disease, Parkinson's disease with and without dementia, and in vascular dementia: an MRI study. Neurology 1996;46:678-681.

110. Seubert P, Motter R, Schenk D, et al. Elevation of CSF tau in early stage Alzheimer's disease. Neurology 1997;46:A161(Abstract).

111. Galasko D, Seubert P, Motter R, et al. CSF levels of A-beta 432 and tau as aids to diagnosing Alzheimer's disease. Neurology 1997;48:A379(Abstract).

112. Reisberg B. Functional Assessment Staging (FAST). Psychopharmacol Bull 1988;24(4):653-659.

113. Reisberg B, Ferris SH, Franssen EH, et al. Mortality and temporal course of probable Alzheimer's disease: a 5-year prospective study. Int Psychogeriatr 1996;8:291-311.

114. Reisberg B, Sclan SG, Franssen E, Kluger A, Ferris SH. Dementia staging in chronic care populations. [Review]. Alzheimer Dis Assoc Disord 1994;8 (Suppl 1):S188-S205

115. Mann UM, Mohr E, Gearing M, Chase TN. Heterogeneity in Alzheimer's disease: progression rate segregated by distinct neuropsychological and cerebral metabolic profiles. J Neurol Neurosurg Psychiatry 1992;55:956-959.

116. Boller F, Becker JT, Holland AL, Forbes MM, Hood PC. Predictors of decline in Alzheimer's Disease. Cortex 1991;27:9-17.

117. Yesavage JA, Brooks JO, Taylor J, Tinkelberg J. Development of aphasia, apraxia, and agnosia and decline in Alzheimer's disease. Am J Psychiatry 1993;150:742-747.

118. Stern Y, Mayeux R, Sano M, Hauser WA, Bush T. Predictors of disease course in patients with probable Alzheimer's disease. Neurology 1987;37:1649-1653.

119. Stern Y, Albert M, Brandt J, et al. Utility of extrapyramidal signs and psychosis as predictors of cognitive and functional decline, 
THE CANADIAN JOURNAL OF NEUROLOGICAL SCIENCES

nursing home admission, and death in Alzheimer's disease: prospective analyses from the Predictors Study. Neurology 1994;44:2300-2307.

120. Jacobs D, Sano M, Marder K, et al. Age at onset of Alzheimer's disease: relation to pattern of cognitive dysfunction and rate of decline. Neurology 1994;44:1215-1220.

\section{Appendix A: DSM-IV Criteria for Dementia ${ }^{4}$}

\section{Electronic reproduction not granted}

Permission granted from the Diagnostic and Statistical Manual of Mental Disorders. Fourth Edition. Copyright 1994 American Psychiatric Association.

\section{Appendix B: NINCDS-ADRDA Criteria for clinical diagnosis of Alzheimer's disease ${ }^{12}$}

Electronic reproduction not granted

McKann G, Drachman D, Folstein M, et al. Clinical diagnosis of Alzheimer's disease - report of the NINCDS-ADRDA Work Group under the auspices of Department of Health and Human Services Task Force on Alzheimer's Disease. Neurology 1984; 1984;34:939-994. (C) 1984 by American Academy of Neurology. Reproduced with permission of Lippincott, Williams and Wilkins 
Appendix C: Consensus criteria for the clinical diagnosis of dementia with Lewy bodies. ${ }^{21}$

\section{Electronic reproduction not granted}

Modified from IG McKeith, D Galasko, K Kosaka, et al. Consensus guidelines for the clinical and pathologic diagnosis of dementia with Lewy bodies (DLB): report of the consortium on DLB international workshop. Neurology 199647: 1113-1124. @ 1996 by American Academy of Neurology. Reproduced with permission of Lippincott, Williams and Wilkins 